\title{
Whitmania Pigra Whitman Extracts Inhibit Lipopolysaccharide Induced Rat Vascular Smooth Muscle Cells Migration and their Adhesion Ability to THP-1 and RAW 264.7 Cells
}

\author{
Shuaishuai $\mathrm{Li}^{1,2}$, Long Cheng ${ }^{1,2}$, Dengkun $\mathrm{An}^{1,2}$, Shuliang Song ${ }^{1,2}$, Hao Liang ${ }^{1,2}$, Fulong Chu ${ }^{1,2}$ and \\ Aiguo $\mathrm{Ji}^{1,2,3}$ \\ Shuaishuai Li and Long Cheng contributed equally to this work. \\ ${ }^{1}$ Marine College, Shandong University, Weihai, China \\ ${ }^{2}$ Weihai International Biotechnology Research and Development Centre, Shandong University, Weihai, China \\ ${ }^{3}$ School of Pharmaceutical Sciences, Shandong University, Jinan, China
}

\begin{abstract}
Aim: Atherosclerosis is a kind of chronic inflammatory disease. A crucial pathology change of atherosclerosis is the migration of activated VSMCs to the intima where they interact with leukocytes by expressing adhesion molecules, including intercellular cell adhesion molecule-1 (ICAM-1) and vascular cell adhesion molecule-1 (VCAM-1). Moreover, monocyte chemoattractant protein-1 (MCP-1) expressed by VSMCs plays an important role in recruiting monocytes and macrophages. Leech (Whitmania pigra Whitman) is a traditional Chinese medicine to treat cardiovascular diseases including atherosclerosis, however previous research has rarely reported the molecular mechanism for its curative effect. Thus, our study focuses on the effects of leech extracts on the expression of inflammatory factors, adhesion molecules and MCP-1 in rat VSMCs.
\end{abstract}

Methods: In our present study, wound-healing assay and Boyden chamber model were applied to evaluate the anti-migration effect of LEE (Leech Enzyme Extracts) on LPS induced VSMCs. The anti-adhesion effect was assessed using DiI-labeled THP-1 and RAW264.7.

Results: LEE suppressed LPS-induced VSMCs migration and decreased the chemotaxis and adhesive capacity of THP-1 and RAW264.7 to LPS-stimulated VSMCs. LEE also attenuated the upregulation of a variety of pro-atherosclerotic factors by inhibiting the phosphorylation of p38 MAPK. LEE was also observed to prevent NF- $\kappa$ B p 65 nuclear localization using immune-fluorescent staining.

Conclusions: In conclusion, LEE suppresses LPS-induced upregulation of inflammatory factors, adhesion molecules and MCP-1 in rat VSMCs mainly via inhibiting the p38 MAPK/NF- $\kappa$ B pathways, thus partly uncovered LEE's molecular mechanisms for its therapeutic effect on atherosclerosis.

Key words: Atherosclerosis, Vascular smooth muscle cells, Vascular cell adhesion molecule-1, Intercellular cell adhesion molecule-1, Mitogen-activated protein kinase (MAPKs)

This article is distributed under the terms of the latest version of CC BY-NC-SA defined by the Creative Commons Attribution License.

\section{Introduction}

Atherosclerosis is a chronic inflammatory disease. A crucial pathology change of atherosclerosis is the migration of activated vascular smooth muscle cells (VSMCs) to the intima where they interact with leu-

Address for correspondence: Shuliang Song, Wenhuaxi Road 180\# (Shandong University), Weihai, Shandong Province, 264209, China

E-mail: songshuliang@wh.sdu.edu.cn

Received: May 24, 2016

Accepted for publication: June 28, 2016 kocytes by expressing adhesion molecules, including intercellular cell adhesion molecule-1 (ICAM-1) and vascular cell adhesion molecule-1 (VCAM-1). Moreover, monocyte chemoattractant protein-1 (MCP-1) expressed by VSMCs plays an important role in recruiting monocytes and macrophages. Studies on the inflammatory processes of atherosclerosis have uncovered several mechanisms that could lead to potential therapies ${ }^{1)}$. Many known risk factors are in close relation with the pathological process of atherosclerosis ${ }^{2)}$. Inflammatory signaling alters the behavior of endothelial cells and VSMCs, which could recruits more 
Table 1. Primer sequences for RT-PCR and their expected product size

\begin{tabular}{llc}
\hline Target & \multicolumn{1}{c}{ Primer sequence $\left(5^{\prime}\right.$ to $\left.3^{\prime}\right)$} & Product size (bp) \\
\hline TLR-4 & F: GGCA TCAT CTTC ATTG TCCT TG & 111 \\
R: AGCA TTGT CCTC CCAC TCG & \\
iNOS & F: TTCA GGTA TGCG GTAT TTGG & 249 \\
R: GTTG GAAG TGTA GCGT TTCG & \\
TNF- $\alpha$ & F: CTTA TCTA CTCC CAGG TTCT CTCA A & 200 \\
$\beta$-actin & R: GAGA CTCC TCCC AGGT ACAT GG & \\
MCP-1 & R: AGAC CTTC AACA CCCC AG & 254 \\
ICAM-1 & F: ATGC AGGT CTCT GTCA CGCT & \\
R: GGTG CTGA AGTC CTTA GGGT & \\
VCAM-1 & F: AAAC GGGA GATG AATG GT & \\
& R: TCTG GCGG TAAT AGGT GTA & 336 \\
& F: GGAG ACAC TGTC ATTA TCTC CTG & \\
\hline
\end{tabular}

$\mathrm{F}$ indicates forward primer; $\mathrm{R}$ indicates reverse primer.

inflammatory cells to promote lesion formation. VSMCs and macrophages are in direct contact, and a variety of adhesion molecules are involved in this process, including VCAM-1 and ICAM-1 ${ }^{3-6)}$. Thus, the VSMCs are capable of retaining macrophages in the lesion of atherosclerosis.

Pro-inflammatory factors produced by VSMCs, endothelial cells, macrophages and T cells can promote the progression of atherosclerosis ${ }^{7)}$. In VSMCs, some of the most important are platelet-derived growth factor (PDGF), macrophage migration inhibitory factor (MIF), inducible NOS (iNOS) and MCP-1 ${ }^{8,9)}$.

Leech has been widely used as a traditional Chinese medicine in cardiovascular diseases ${ }^{10-12)}$. Our previous studies have investigated the anti-atherosclerosis effect of LEE (leech enzyme extracts) from Whitmania pigra Whitman using ApoE $\mathrm{E}^{-1-}$ mice, and found the treatment of LEE could obviously attenuate the area of atherosclerosis lesion. This effect is dose dependent and mainly a result of a reduced invasion of macrophages in the artery walls ${ }^{13)}$. However, it remains unclear whether LEE can affect the abilities of VSMCs in recruiting and retaining macrophages. Therefore, our present study was aimed at uncovering the effects of LEE on the expression pro-inflammatory mediators, adhesion molecules and MCP-1 in VSMCs.

\section{Materials and Methods}

\section{Materials}

Antibodies for TLR4, MCP-1, iNOS, ICAM-1, VCAM-1, p38MAPK, p-p38MAPK, JNK1/2, p-JNK $1 / 2$, ERK1/2, p-ERK1/2, $\beta$-actin were used for west- ern blot. Trizol reagent, Revert Aid ${ }^{\mathrm{TM}}$ First Strand cDNA Synthesis Kit and Dream Taq ${ }^{\mathrm{TM}}$ PCR Master Mix were used for RT-PCR. NF- $\kappa$ B nuclear translocation assay kit, total nitric oxide assay kit and 1,1'dioctadecyl-3,3,3',3'-tetramethylindocarbocyanine perchlorate (DiI), were from Beyotime Institute of Biotechnology (Shanghai, China). Positive drug simvastatin (SIM) was obtained from National Institutes for Food and Drug Control (Beijing, China). LEE was obtained from the International Biotechnology Research and Development Center of Shandong University at Weihai using our previous procedure ${ }^{13)}$.

\section{VSMCs Isolation and LEE Treatment}

Male Sprague-Dawley rats were obtained from the School of Medicine at Shandong University. VSMCs were isolated from the thoracic aorta and cultured in DMEM containing 10\% FBS, $100 \mathrm{U} / \mathrm{mL}$ penicillin and $100 \mu \mathrm{g} / \mathrm{mL}$ streptomycin ${ }^{14)}$. LEE was obtained from the International Biotechnology Research and Development Center of Shandong University at Weihai using a previous procedure ${ }^{13)}$.

VSMCs were subjected to six conditions: (1) LPS $(1.0 \mu \mathrm{g} / \mathrm{mL})$ as model control; (2) LPS $(1.0 \mu \mathrm{g} / \mathrm{mL})+$ $\operatorname{SIM}(10 \mu \mathrm{M})$ as positive control; (3) LPS $(1.0 \mu \mathrm{g} / \mathrm{mL})$ + LEE $(50 \mu \mathrm{g} / \mathrm{mL}) ;(4) \quad \operatorname{LPS}(1.0 \mu \mathrm{g} / \mathrm{mL})+\operatorname{LEE}(100$ $\mu \mathrm{g} / \mathrm{mL}) ;(5) \mathrm{LPS}(1.0 \mu \mathrm{g} / \mathrm{mL})+\operatorname{LEE}(200 \mu \mathrm{g} / \mathrm{mL})$; (6) $\mathrm{LPS}(1.0 \mu \mathrm{g} / \mathrm{mL})+\operatorname{LEE}(400 \mu \mathrm{g} / \mathrm{mL})$.

\section{THP-1 and RAW264.7 Cell Culture}

Human monocytic cell line THP-1 and murine monocyte-macrophage-like cell line RAW264.7 were obtained from the Institute of Biochemistry and Cell 


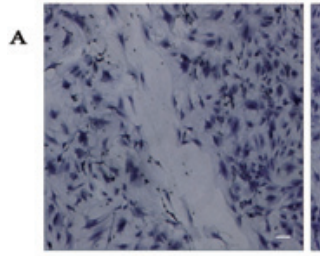

Con

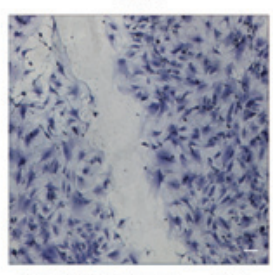

LPS+LEE $(100 \mu \mathrm{g} / \mathrm{ml})$

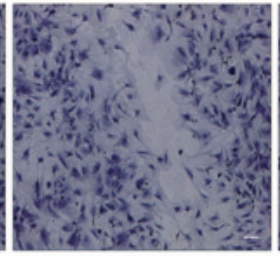

LPS

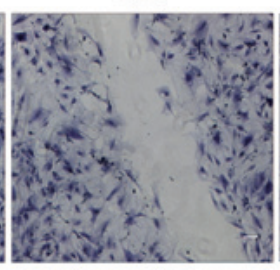

LPS+LEE $(200 \mu \mathrm{g} / \mathrm{ml})$



LPS+SIM

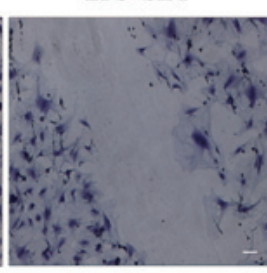

LPS+LEE $(400 \mu \mathrm{g} / \mathrm{ml})$

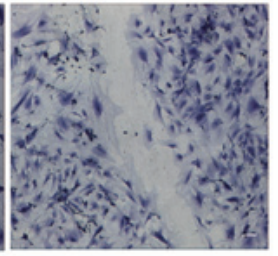

LPS+LEE $(50 \mu \mathrm{g} / \mathrm{ml})$



Con



LPS+LEE $(100 \mu \mathrm{g} / \mathrm{ml})$


LPS+LEE $(200 \mu \mathrm{g} / \mathrm{ml})$
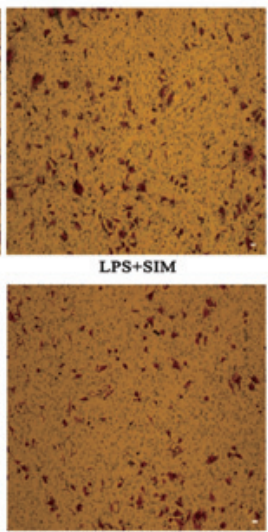

LPS+LEE $(400 \mu \mathrm{g} / \mathrm{ml})$

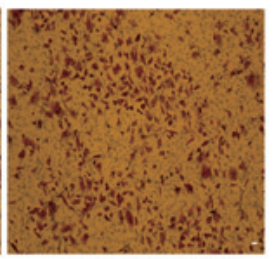

LPS +LEE $(50 \mu \mathrm{g} / \mathrm{ml})$

Fig. 1. The anti-migration effects of LEE

(A) LEE inhibited wound healing in LPS-induced VSMCs. Bar $=50 \mu \mathrm{m}$. (B) LEE inhibited LPS-induced VSMCs migrating in a Boyden chamber assay. $B a r=50 \mu \mathrm{m}$. (C) The healing rate and anti-migration rate of the wound-healing assay. (D) Number of VSMCs migration. ${ }^{\sharp} P<0.05$ vs control, ${ }^{*} P<0.05$ vs LPS, $\Delta P<0.05$ vs LPS + SIM. Data are from three independent experiments.

Biology in Shanghai and cultured in DMEM medium containing $10 \% \mathrm{FBS}, 100 \mathrm{U} / \mathrm{mL}$ penicillin and 100 $\mu \mathrm{g} / \mathrm{mL}$ streptomycin. Both these cell lines are commonly used to study the biology of monocyte and macrophage ${ }^{15,16)}$.

\section{Wound-healing Assay in vitro}

The VSMCs were grown to confluence in 24-well plates. After starving in serum-free DMEM medium for $24 \mathrm{~h}$, a sterile pipette tip was used to create a straight scratch through the center of each well ${ }^{17)}$. Cells were incubated with or without LPS, SIM and LEE. The wounds were photographed and analyzed at $48 \mathrm{~h}$ after the scratch.

\section{The VSMCs Migration Assay}

A modified Boyden chamber with an $8 \mu \mathrm{m}$ pore size was used for the VSMCs migration assay ${ }^{18)}$. Briefly, $100 \mu$ of serum-free cell suspension $\left(2 \times 10^{4}\right.$

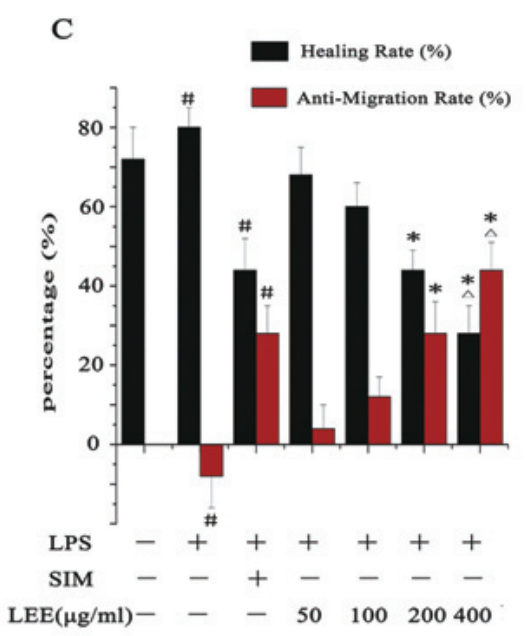

$\mathbf{D}$

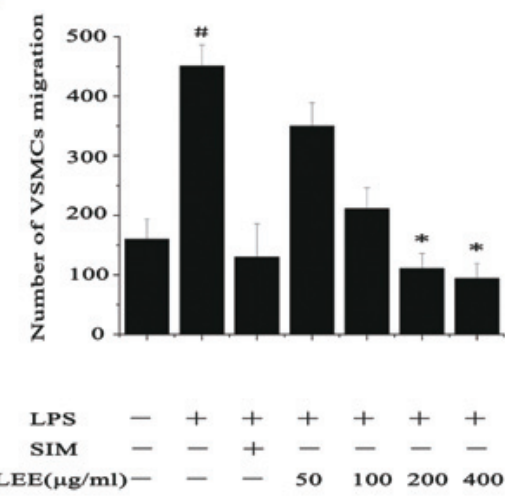

cells) was added to the upper surface of the chamber whose basement membrane had been embedded with Matrigel. The lower chambers were filled with DMEM $(500 \mu l)$ supplemented with LPS, LPS + SIM or LPS + LEE. The chambers were incubated at $37^{\circ} \mathrm{C}$ to allow for cell migration. After removal of the cells on the upper surface, the cells on the lower surface were fixed with $4 \%$ paraformaldehyde. Crystal violet $(0.1 \%)$ was used to stain the migration cells. Five random areas of cells per membrane were counted using a microscope.

\section{The THP-1 and RAW264.7 Chemotaxis Assay}

The lower chambers were filled with DMEM supplemented with culture supernatant of the VSMCs which had been incubated in relevant conditions according to the planned six groups mentioned up. THP-1 cells were added to the top of the chamber. After incubation for $12 \mathrm{~h}$ at $37^{\circ} \mathrm{C}$, the upper chambers 

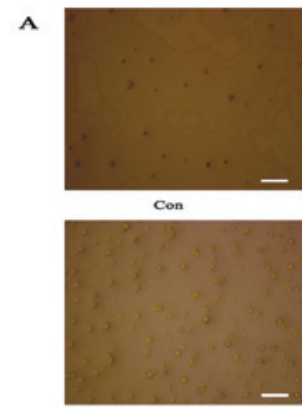

LPS+LEE $(100 \mu g / \mathrm{ml})$

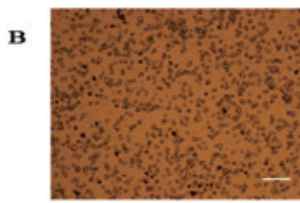

Con

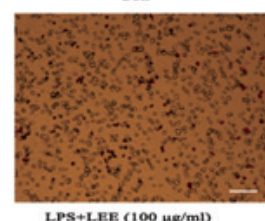

LPS+LEE (100 $\mu \mathrm{g} / \mathrm{ml})$

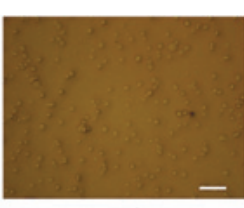

LPS

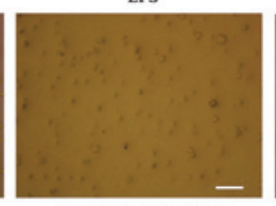

LPS+LEE (200 $\mu \mathrm{g} / \mathrm{ml})$

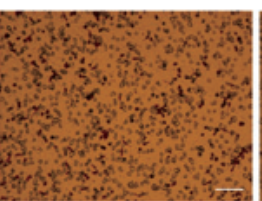

LPS

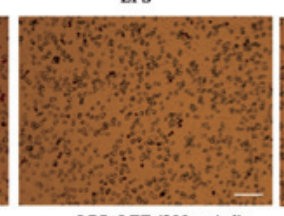

LPS+LEE (200 $\mu \mathrm{g} / \mathrm{ml})$

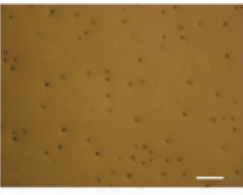

LPS+SIM

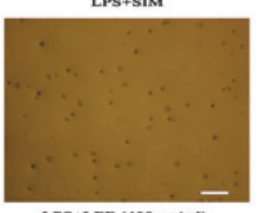

LPS +LEE ( $400 \mu g / \mathrm{mi})$

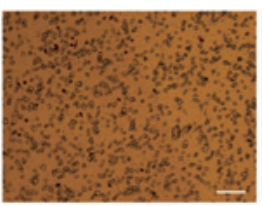

LPS+SIM

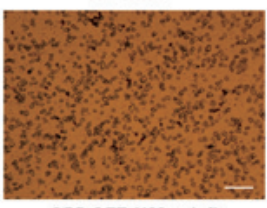

LPS+LEE (400 $\mu \mathrm{g} / \mathrm{ml})$

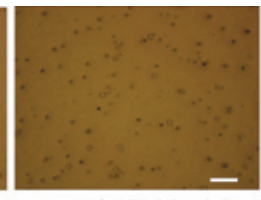

LPS+LEE (SO $\mu \mathrm{g} / \mathrm{ml})$

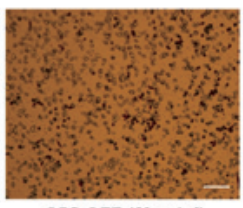

LPS+LEB ( $(50 \mu \mathrm{ge} / \mathrm{ml})$

Fig. 2. The anti-chemotaxis effects of LEE

(A) Inhibition of chemotaxis of THP-1 cells to LPS-stimulated VSMCs by LEE in a Boyden chamber assay. Bar $=100 \mu \mathrm{m}$. (B) Inhibition of chemotaxis of RAW264.7 cells to LPS-stimulated VSMCs by LEE in a Boyden chamber assay. Bar $=100 \mu \mathrm{m}$. (C) Number of THP-1 migration. (D) Number of RAW264.7 migration. ${ }^{\#} P<0.05$ vs control, ${ }^{*} P<0.05$ vs LPS, ${ }^{* *} P<0.01$ vs LPS. Data are from three independent experiments.

were removed, and then THP-1 cells in the lower chambers were observed under phase contrast microscope after conventional centrifugal operation. As for RAW264.7, after removal of the cells on the upper surface, the cells on the lower surface were fixed with $4 \%$ paraformaldehyde. Crystal violet $(0.1 \%)$ was used to stain the migration cells. Five random areas per membrane were counted using a microscope.

\section{The THP-1 and RAW264.7 Adhesion Assay}

The cell adhesion assay was performed as described previously ${ }^{19)}$. The VSMCs were treated with LPS or LPS with SIM or LPS with LEE in 24-well plates. THP-1 or RAW264.7 monocytes $\left(2.5 \times 10^{5}\right.$ cells $/ \mathrm{mL}$ ) labeled with DiI was added to each well. After incubation for $2 \mathrm{~h}$, the unbound cells were aspirated. Five fields were captured using a fluorescence microscope and the numbers of adherent cells were counted.

\section{RT-PCR}

Total RNA was isolated using Trizol reagent, and was quantified spectrophotometrically at a ratio of 260-280 nm. RT-PCR was performed by using an RT-PCR System kit according to the protocol, with primers for rat TLR4, TNF- $\alpha$, iNOS, MCP-1, ICAM-1, VCAM- 1 , and $\beta$-actin. The PCR amplification procedure was performed with denaturation at $95^{\circ} \mathrm{C}$ for $30 \mathrm{~s}$, annealing at Tm for $30 \mathrm{~s}$ and DNA extending at $72^{\circ} \mathrm{C}$ for $60 \mathrm{~s}$. A total of 30 amplification cycles were carried out. The PCR products were electrophoresed in $1.2 \%$ agarose gel. After staining with ethidium bromide, the total cDNA was determined by UV spectroscopy. $\beta$-Actin was utilized as a housekeeping gene as indicated. Primers for RT-PCR are listed in Table 1.

\section{Western Blot}

The VSMCs were lysed with RIPA, and the supernatants were collected after centrifugation at 10 $000 \mathrm{rpms}$ for $5 \mathrm{~min}$ at $4^{\circ} \mathrm{C}$. Protein concentrations were measured using the BCA protein assay kit using bovine serum albumin. Samples were separated by SDS-PAGE and transferred to a polyvinylidene difluoride (PVDF) membrane. After blocking with 5\% fatfree milk in TBST (20 mM Tris- $\mathrm{HCl}(\mathrm{pH}$ 7.6), 150 $\mathrm{mM} \mathrm{NaCl}, 0.1 \%$ Tween 20), the PVDF membrane was incubated with primary antibodies at $4{ }^{\circ} \mathrm{C}$ overnight. Then the PVDF membrane was washed three times in TBST before incubating with horseradish 

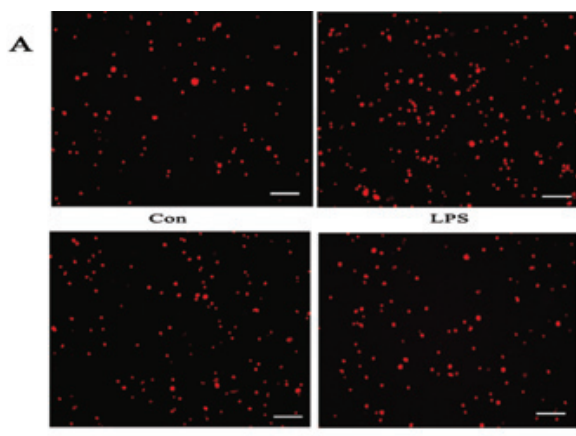

LPS+LEE $(100 \mu \mathrm{\mu g} / \mathrm{ml})$

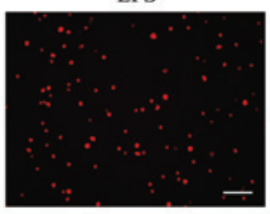

LPS+LEB $(200 \mu \mathrm{g} / \mathrm{ml})$
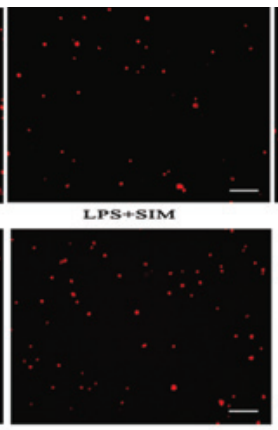

LPS+LEE (400 $\mu \mathrm{g} / \mathrm{ml})$

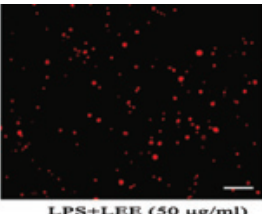

$\mathbf{B}$
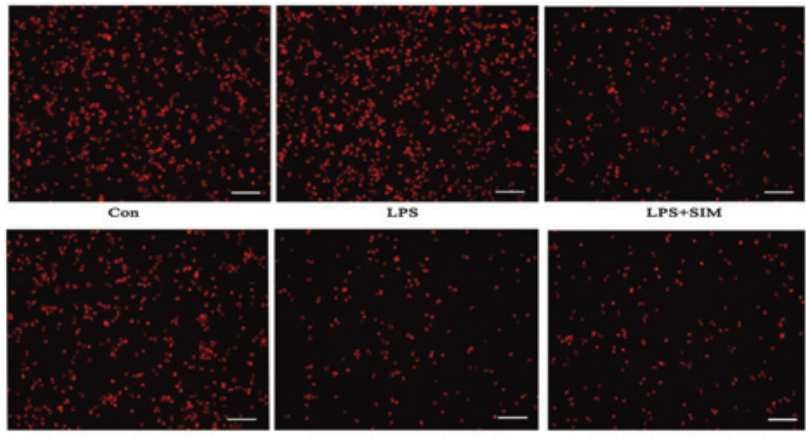

LPS+LEE (200

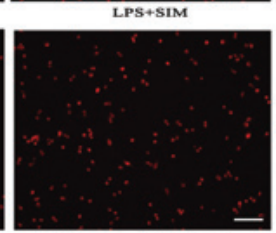

LPS+LEE $(400 \mu \mathrm{g} / \mathrm{ml})$
C
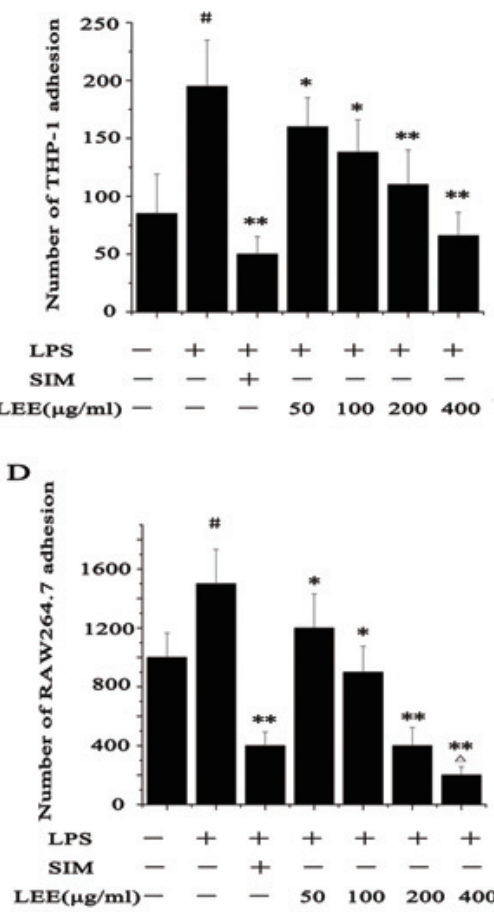

Fig. 3. The anti-adhesion effects of LEE

(A) Inhibition of adhesion of THP-1 cells to LPS-stimulated VSMCs by LEE. Bar=100 $\mu \mathrm{m}$. (B) Inhibition of adhesion of RAW264.7 cells to LPS-stimulated VSMCs by LEE. Bar $=100 \mu \mathrm{m}$. (C) Number of THP-1 adhesion. (D) Number of RAW264.7 adhesion. ${ }^{\#} P<0.05$ vs control, ${ }^{*} P<0.05$ vs LPS, ${ }^{* *} P<0.01$ vs LPS, $\Delta P<0.05$ vs LPS + SIM. Data are from three independent experiments.

peroxidase-conjugated secondary antibodies for 120 min. The optical densities of bands were quantified by using Image J. $\beta$-Actin was the endogenous control, and results were expressed relative to control.

\section{Immuno-fluorescent Staining}

The VSMCs were fixed in $4 \%$ paraformaldehyde and incubated overnight at $4{ }^{\circ} \mathrm{C}$ with rabbit anti$\mathrm{NF}-\kappa \mathrm{B}$ p65 IgG. Cell samples were washed and further incubated with biotinylated anti-rabbit IgG for 1 h. After washing, the cell samples were incubated with 4',6-diamidino-2-phenylindole (DAPI) for $30 \mathrm{~min}$. $\mathrm{NF}-\kappa \mathrm{B}$-positive cells were counted in three separate sections using a fluorescent microscope.

\section{Statistical Analysis}

Data were described as mean $\pm \mathrm{SD}$. Differences between groups were assessed by one-way ANOVA. Statistical tests were done with SPSS software (International Business Machines Corporation, USA). A value of $P<0.05$ was considered as the criteria of statistical significance. ${ }^{\#} P<0.05$ vs control, ${ }^{*} P<0.05$ vs LPS, ${ }^{* *} P<0.01$ vs LPS, $\Delta P<0.05$ vs LPS + SIM.

\section{Results}

\section{VSMCs Wound-healing Assay}

There were two terms we needed to give new meanings to: Healing rate and anti-migration rate. The following two formulas could account for the implications of these two terms: Healing rate $=($ the initial gap width - the later gap width)/the initial gap width; anti-migration rate= (the later gap width of group $\mathrm{X}$-the later gap width of group control)/the initial gap width of group X. Compared with the normal control group, the mobility of the LPS and the SIM group differed greatly. More importantly, the potential performance of LEE was equal to that of SIM $(10 \mu \mathrm{M})$ in inhibiting VSMCs migration in the concentration of $200 \mu \mathrm{g} / \mathrm{mL}$ (Fig. 1A and 1C).

\section{LEE Attenuates VSMCs Migration and Decreases the Chemotaxis of THP-1 and RAW264.7}

The modified Boyden chamber was involved in these experiments. The anti-migration effect of LEE was consistent with the result of the VSMC scratch healing assay in the previous section. The migration rate of VSMCs could be reduced to below that of the 

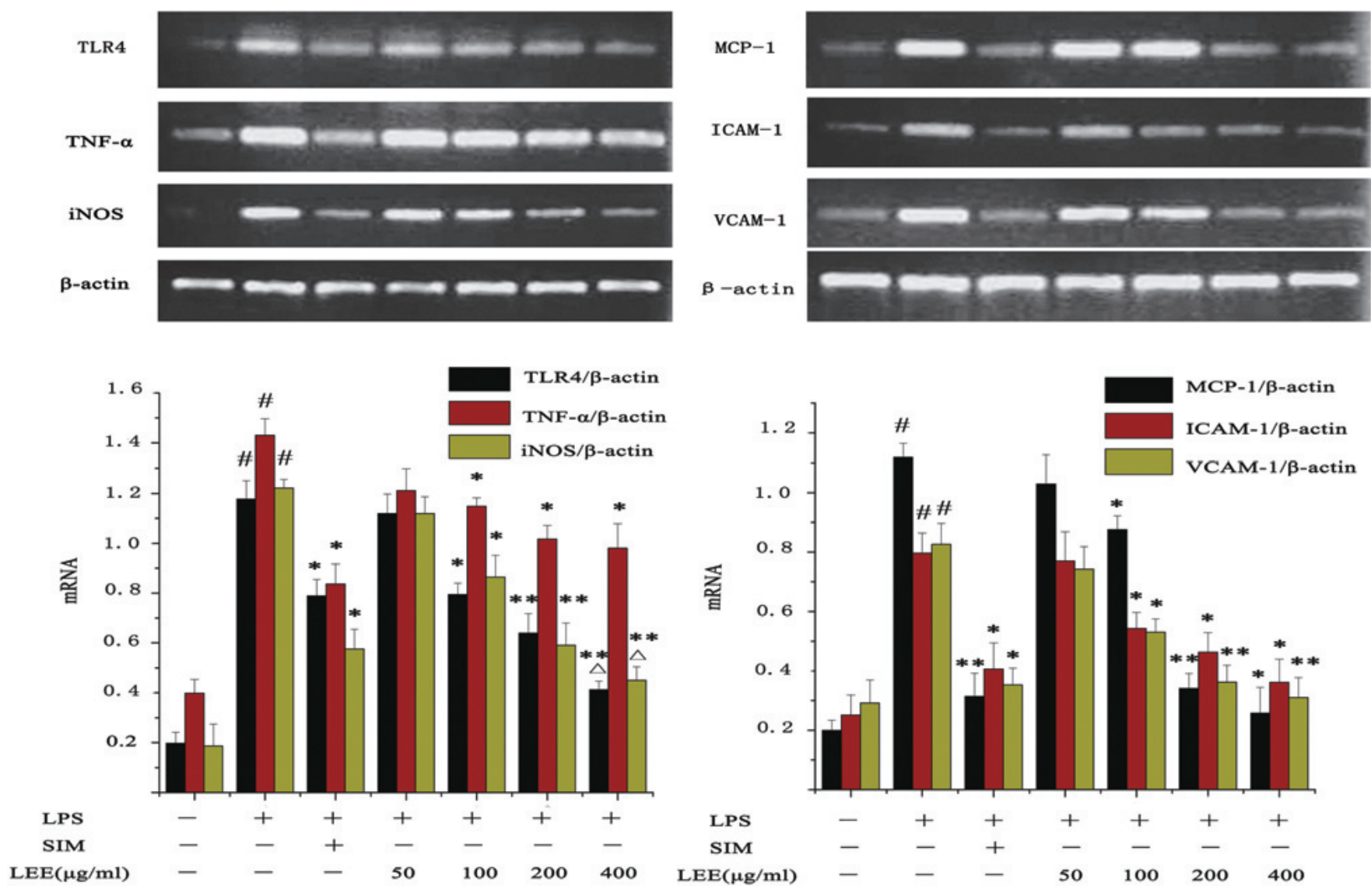

Fig. 4. Inhibitory effect of LEE on LPS-induced mRNA production in VSMCs

Total RNA was extracted and detected by RT-PCR. $\beta$-actin was chosen as a reference. ${ }^{*} P<0.05$ vs control, ${ }^{*} P<0.05$ vs LPS, ${ }^{* *} P<0.01$ vs LPS, $\Delta P<0.05$ vs LPS + SIM. Data are from three independent experiments.

control group with LEE of $200 \mu \mathrm{g} / \mathrm{mL}$ (Fig. 1B and 1D).

In order to study whether LEE has an influence to the chemotaxis of THP-1 or RAW264.7 to LPSstimulated VSMCs, we proposed a parameter on the chemotaxis inhibition rate, which was a function of the cell migration rate. The calculation method for MIR (migration inhibition rate) $=1-($ the number of cell migration in X group - the number of cell migration in blank control)/(the number of cell migration in model group - the number of cell migration in blank control). LEE $(200 \mu \mathrm{g} / \mathrm{mL})$ could decrease the chemotaxis of THP-1 and RAW264.7 to LPS-stimulated VSMCs, and the inhibition rate of those two experiments were $60 \%$ and $80 \%$ respectively (Fig. 2 ).

\section{LEE Decreases the Adhesion of THP-1 and RAW264.7 to LPS-stimulated VSMCs}

The calculation method for the adhesion inhibition rate (AIR) was similar to that of MIR. The formula for $A I R=1-($ the number of cell adhesion in $\mathrm{X}$ group - the number of cell adhesion in blank control)/ (the number of cell adhesion in model group-the number of cell adhesion in blank control). Our data clearly showed that the number of adherent cells gradually reduced with the increase of LEE concentration. LEE $(200 \mu \mathrm{g} / \mathrm{mL})$ could decrease the adhesion of THP-1 and RAW264.7 to LPS-stimulated VSMCs, and the inhibition rate of those two experiments were $76 \%$ and $220 \%$ respectively (Fig. 3 ).

\section{Effect of LEE on Expression of Adhesion Molecule and MCP-1 in VSMCs}

LPS stimulation caused an increased secretion of inflammatory factor, adhesion molecule and MCP-1. The LEE inhibited the upregulation of TLR4, TNF- $\alpha$ and iNOS in VSMCs at the mRNA and protein level. However, LEE could probably specialize in reducing the expression of ICAM-1, VCAM-1 and MCP-1 compared with the inhibitory effect on inflammatory factors, particularly as even the highest concentration of LEE would not be able to reduce the generation of 

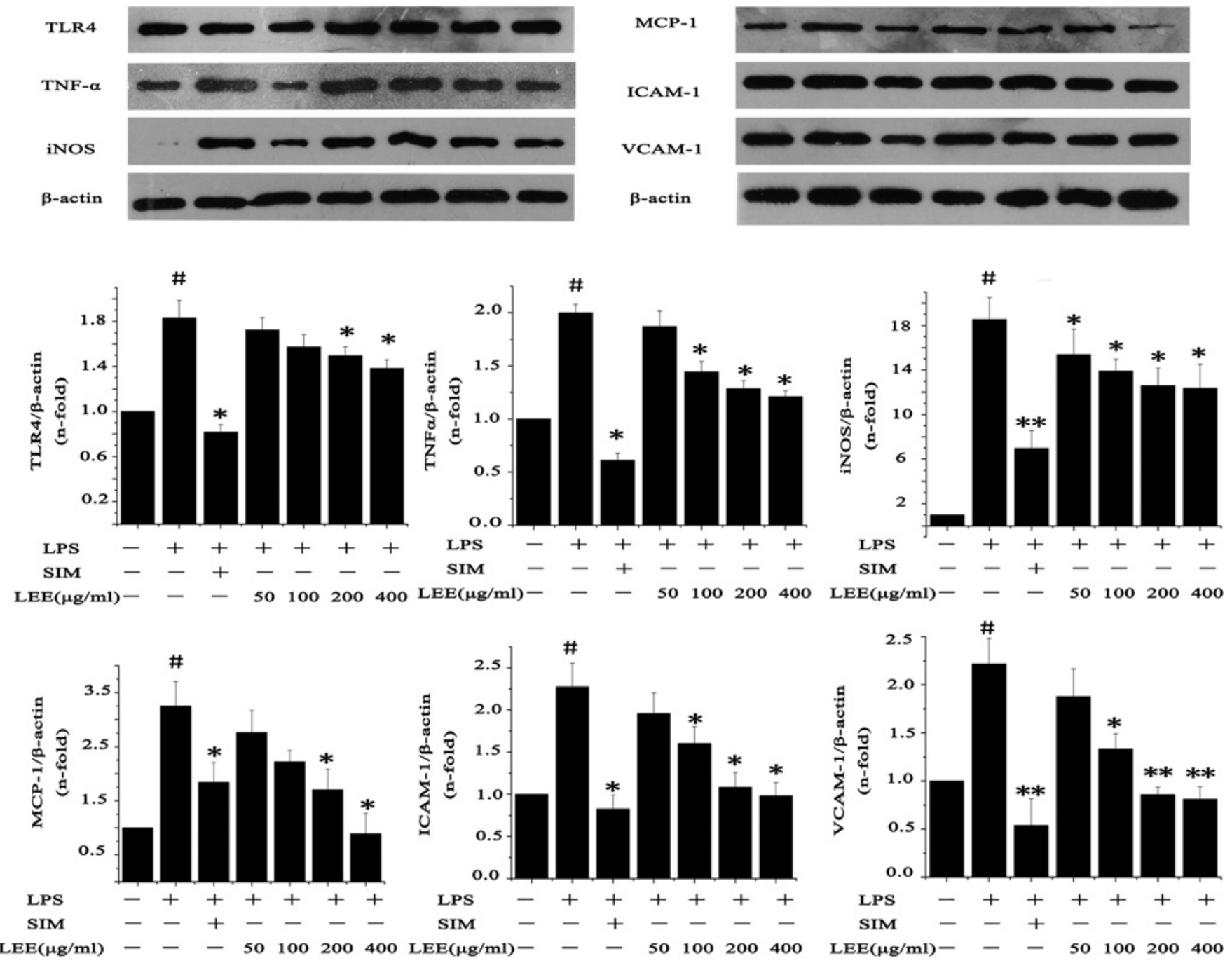

Fig. 5. Inhibitory effect of LEE on LPS induced proteins production in VSMCs

VSMCs were pretreated with LPS $(1 \mu \mathrm{g} / \mathrm{mL})$ for $24 \mathrm{~h}$, and then treated with LEE for another $24 \mathrm{~h}$. Total protein was extracted and then detected by western blotting. ${ }^{*} P<0.05$ vs control, ${ }^{*} P<0.05$ vs LPS, ${ }^{* *} P<0.01$ vs LPS. Data are from three independent experiments.

TNF- $\alpha$ mRNA significantly. In other words, if SIM was taken into consideration, the anti-inflammatory effect of LEE would be slightly less than SIM. In spite of this, LEE could reduce the expression of ICAM-1, VCAM-1 and MCP-1 to normal levels (Fig. 4, 5).

\section{LEE Prevents the NF- $\boldsymbol{\kappa}$ B Translocation to Nucleus}

The activation of NF- $\kappa$ B contributes to inflammation status by promoting the expression of inflammation genes. To verify NF- $\kappa \mathrm{B}$ p 65 nuclear translocation, we analyzed VSMCs by fluorescence microscopy and the depth of the magenta color illustrated the degree of p65 translocation. Our results revealed that LPS significantly increased nuclear translocation of NF- $\kappa \mathrm{B}$ p 65 which could be prevented by LEE treatment (Fig. 6).

\section{Effect of MAPK and NF- $\boldsymbol{\kappa}$ B Inhibitors}

The SB203580 (p38 MAPK inhibitor), U0126 (ERK inhibitor), SP600125 (JNK inhibitor) and PDTC (the NF- $\kappa$ B inhibitor) inhibited the expression of proteins mentioned above in the LPS-induced VSMC. These results indicated that these signaling pathways are involved in the LPS-induced inflammation process (Fig. 7 ).

\section{LEE Inhibits LPS-induced Phosphorylation of p38 MAPK, ERK and JNK in VSMCs}

LPS-induced phosphorylation of ERK1/2, p38 MAPK and JNK1/2 in VSMCs was attenuated by LEE treatment to a different degree. Our results showed that the p38 MAPK signaling pathway was involved in LEE's inhibition in VSMCs while the JNK is only 


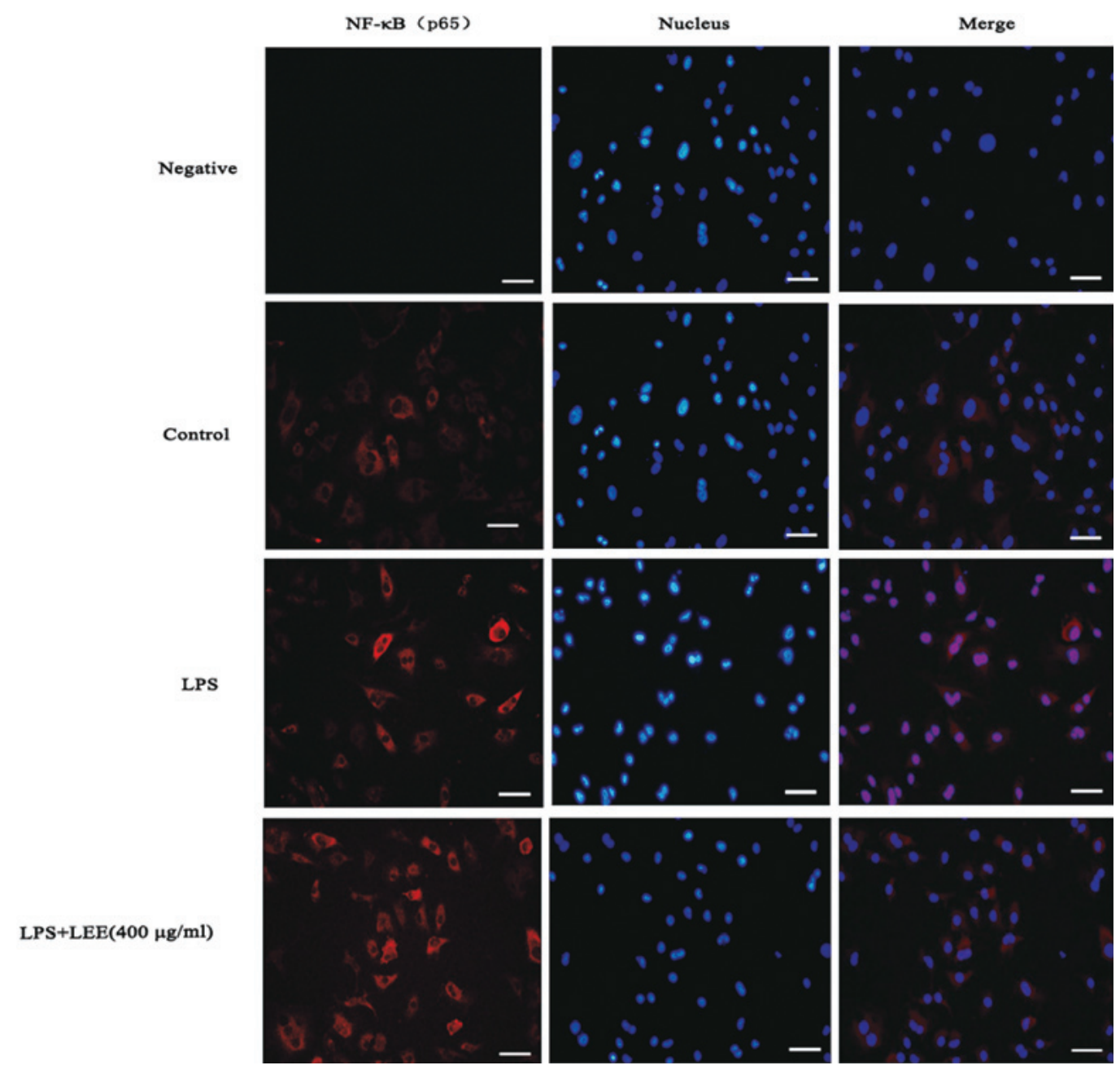

Fig. 6. Effect of LEE on nuclear accumulation of p65 induced by LPS in VSMCs

Confluent VSMCs monolayers were grown on coverslips followed by being incubated with different conditions in the 24-hole plates for $48 \mathrm{~h}$. Then cells were fixed, permeabilized, and stained with anti-p65 antibody and a secondary antibody conjugated to fluorescent red. The DNA was stained using DAPI. The negative control (p65 antibody not added) and a blank control are both included.

slightly involved in this process (Fig. 8).

\section{Discussion}

Atherosclerosis is a chronic inflammatory disease. Studies have revealed that endothelial cells, VSMCs and inflammatory cells are involved in atherosclerosis pathological process ${ }^{7}$. The migration and proliferation of VSMCs play an important role in the process of intimal thickening, which is an important pathogenic change of atherosclerosis. Leech (Whitmania pigra Whitman) is a traditional Chinese medicine included in Chinese Pharmacopoeia (2010) to treat cardiovascular diseases including atherosclerosis, however previous research has rarely reported the molecular mechanism for its curative effect. Thus, our study focuses on the effects of leech extracts on the expression of inflammatory factors, adhesion molecules and MCP-1 in rat VSMCs.

The VSMCs express the cellular adhesion molecules and chemokines in atherosclerosis ${ }^{8)}$. Thus, effective block of these proteins may help to ameliorate the development of atherosclerosis. In this study, we revealed that LEE is capable of inhibiting LPSinduced upregulation of adhesion molecules ICAM-1, VCAM-1 and one chemokine MCP-1 in VSMCs in a concentration-dependent manner. In parallel with these results, migration and adhesion of THP-1 and RAW 264.7 to LPS-activated VSMCs was markedly decreased by LEE. To our knowledge, this is the first report on the inhibiting effect of LEE on adhesion molecules and MCP-1 expression in VSMCs.

Although NO production by the enzyme eNOS 


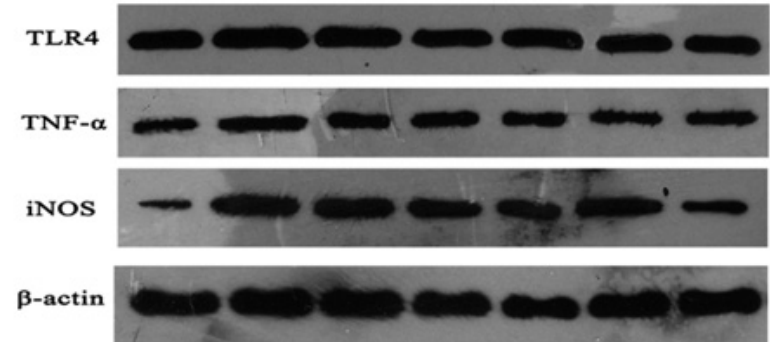

A
B

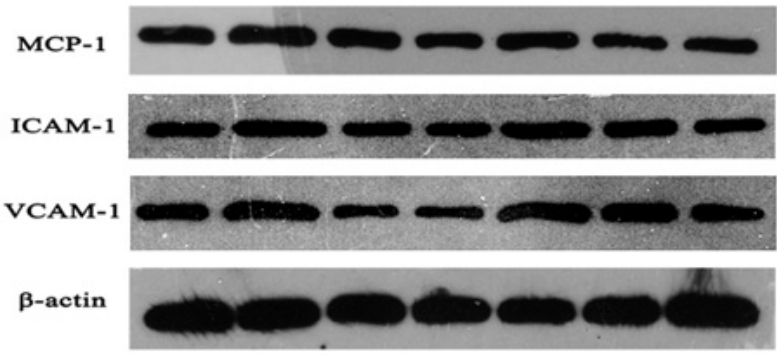

C
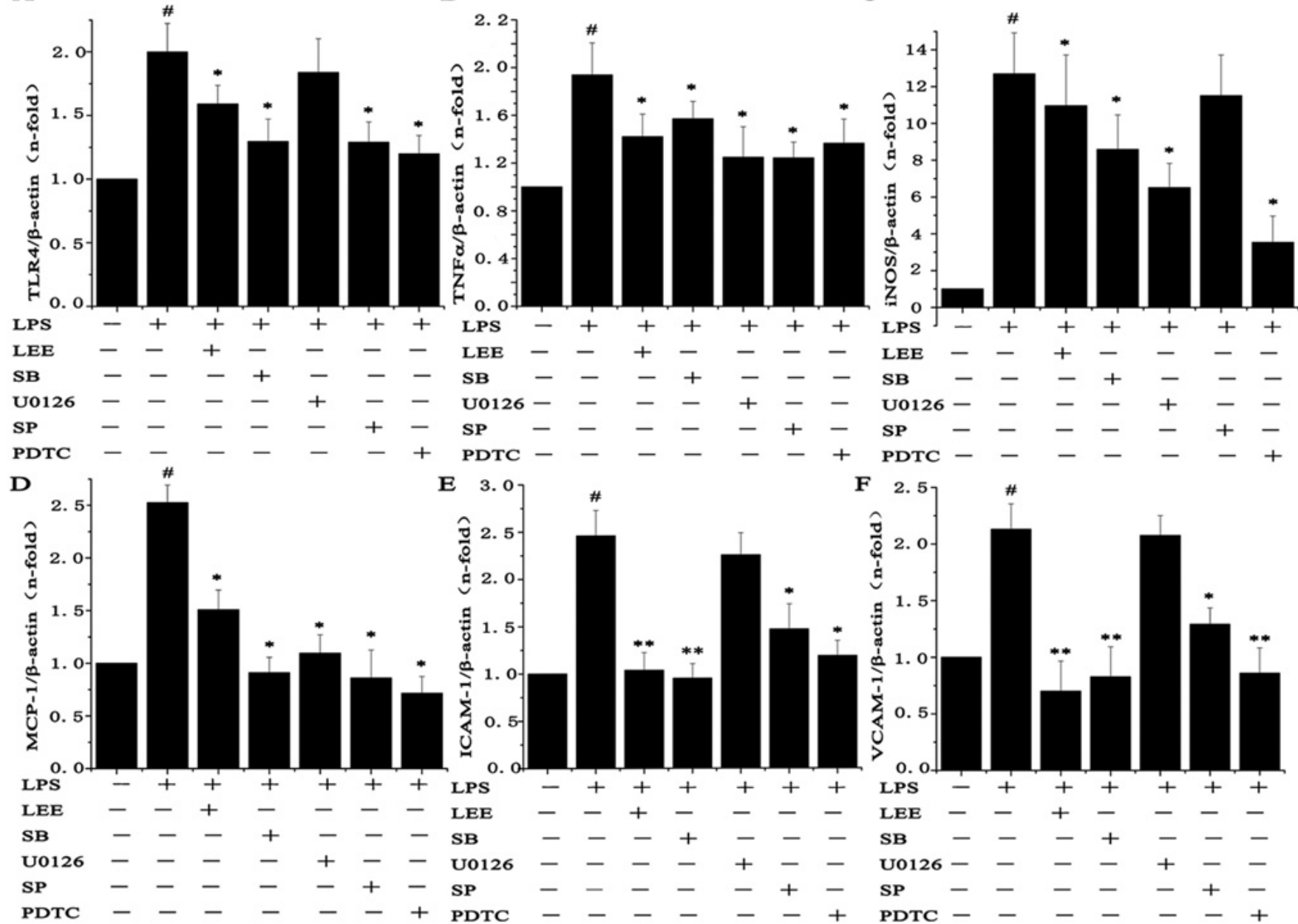

Fig. 7. Effect of inhibitors to MAPKs and NF- $\kappa$ B on LPS-induced proteins upregulation

VSMCs were pre-treated with SB203580 $(25 \mu \mathrm{mol} / \mathrm{L})$, U0126 $(20 \mu \mathrm{mol} / \mathrm{L})$, SP600125 $(15 \mu \mathrm{mol} / \mathrm{L})$ and PDTC $(80 \mu \mathrm{mol} / \mathrm{L})$ for $1 \mathrm{~h}$ before adding LEE $(400 \mu \mathrm{g} / \mathrm{mL})$, and then incubated with $1 \mu \mathrm{g} / \mathrm{mL}$ LPS for another $24 \mathrm{~h} .{ }^{*} P<0.05$ vs control, ${ }^{*} P<0.05$ vs LPS, ${ }^{* *} P<0.01$ vs LPS. Data are from three independent experiments.

has been found to be beneficial in preventing atherosclerosis ${ }^{20)}$, high $\mathrm{NO}$ production will increase oxidative stress, which is a risk factor for atherosclerosis ${ }^{21)}$. Thus, inhibition of iNOS and subsequent overproduction of NO could be helpful to treat atherosclerosis. Our results showed that LEE inhibited iNOS both at the mRNA and protein level in LPS-stimulated VSMCs. Additionally, NO production was suppressed by LEE, providing a novel molecular mechanism for its anti-atherosclerotic effects.

Chemokine and their receptors play an important role in the pathogenesis of atherosclerosis. Tolllike receptor 4 (TLR4) is a kind of pattern recognition receptor which can activate inflammatory signaling pathways when combined with LPS ${ }^{22-25)}$. TLR4 is overexpressed in human atherosclerotic plaques, and 

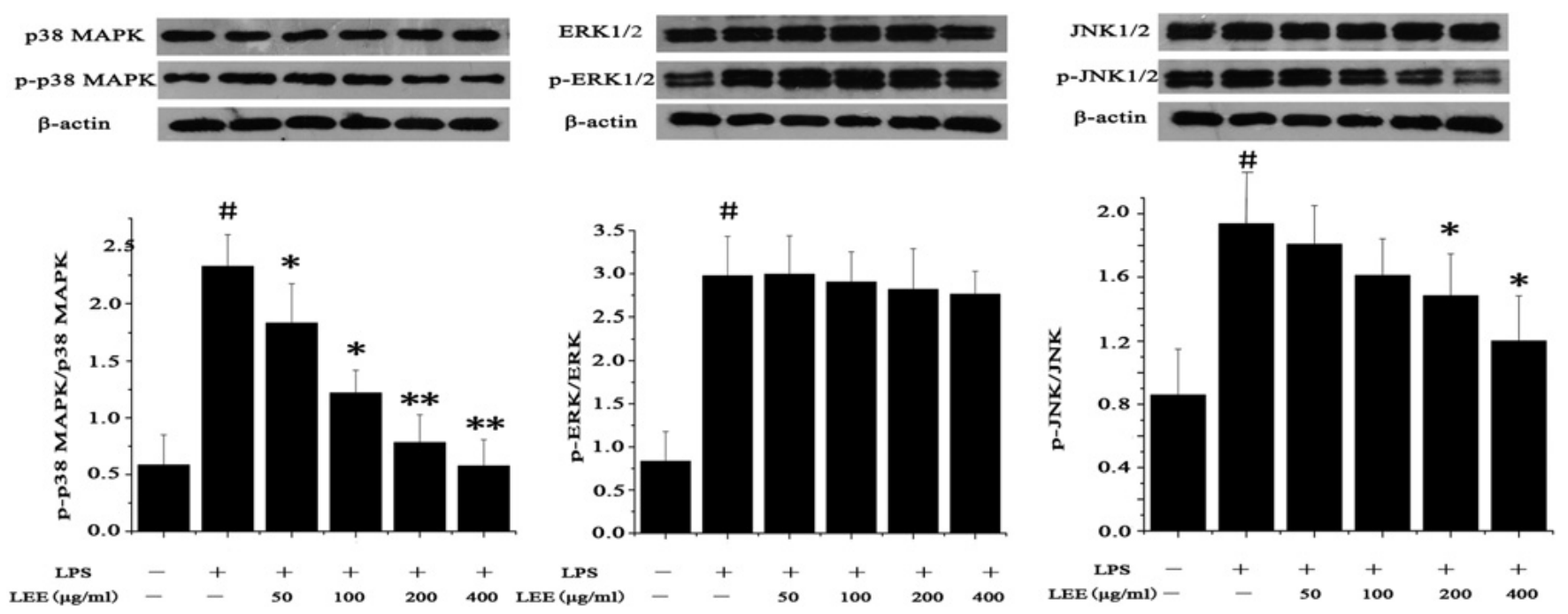

Fig. 8. Effect of LEE on MAPK signaling pathway in LPS-stimulated VSMCs

Cells were stimulated with LPS for $12 \mathrm{~h}$, and then were treated with LEE for $24 \mathrm{~h}$. Western blot analysis was subsequently used to detect the expression of p38 MAPK, ERK and JNK. Phosphorylated proteins were also detected. ${ }^{\#} P<0.05$ vs control, ${ }^{*} P<0.05$ vs LPS, ${ }^{* *} P<0.01$ vs LPS. Data are from three independent experiments.

TLR4 gene knockout mice showed reduced plaques area and vulnerability ${ }^{26}$. In our study, LEE inhibited LPS-induced upregulation of TLR4, which could activate following signal transduction that triggers inflammatory responses. MCP-1 and TNF- $\alpha$ are, respectively, the major chemokine and pro-inflammatory cytokines involved in atherosclerosis ${ }^{27-29)}$. Consistent with previous reports, we found that LPS increased TNF- $\alpha$ and MCP-1 expression in VSMCs. More importantly, LEE inhibited LPS-induced upregulation of these two factors in a dose-dependent manner.

Mitogen-activated protein kinases (MAPKs) are a group of signaling molecules that regulate inflammatory, proliferation, apoptosis and differentiation through activating several downstream transcription factors $^{30,31)}$. The NF- $\kappa$ B signaling pathway can be activated by several atherogenic stimuli, serving as a regulator in inflammatory genes ${ }^{32,33)}$. Thus, NF- $\kappa \mathrm{B}$ activation pathway can be recognized as a potential therapeutic target for atherosclerosis in clinical applications $^{34)}$. NF- $\kappa \mathrm{B}$ is partially dependent on the phosphorylation of MAPKs ${ }^{35)}$. Our data support that LEE markedly inhibited the phosphorylation of p38 MAPK and the nuclear translocation of NF- $\kappa \mathrm{B}$ in LPS-stimulated VSMCs.

A limitation of the study was that the LEE used in this study are crude extracts from leech. In light of this the present study provides a preliminary explanation for the widespread clinical application of leech (Whitmania pigra Whitman) in the treatment of atherosclerosis. In further studies, focus should be put on the separation and purification procedures, which are necessarily required to give more information on the specific effective constituents included in LEE. In conclusion, our results showed that LEE markedly inhibited LPS-induced overproduction of inflammatory factors, adhesion molecules and MCP-1 in VSMCs. Additionally, LEE's beneficial effects on atherosclerosis are at least partially depending on p38 $\mathrm{MAPK} / \mathrm{NF}-\kappa \mathrm{B}$ signaling pathway.

\section{Acknowledgments}

This study does not bear any conflict. This work was supported by the National Natural Science Foundation of China (No. 81371455) and Shandong Provincial Natural Science Foundation, China (2015ZRE 27131).

\section{COI}

All authors approved the final submission and declare that no potential competing interests exist.

\section{References}

1) Weber C, Noels H. Atherosclerosis: current pathogenesis and therapeutic options. Nat. Med. 2011; 17: 1410-1422

2) Libby P. Inflammation in atherosclerosis. Arterioscler. Thromb. Vasc. Biol. 2012; 32: 2045-2051

3) Mestas J, Ley K. Monocyte-Endothelial Cell Interactions in the Development of Atherosclerosis. Trends Cardio- 
vasc. Med. 2008; 18: 228-232

4) Koga J, Aikawa M. Crosstalk between macrophages and smooth muscle cells in atherosclerotic vascular diseases. Vascul. Pharmacol. 2012; 57: 24-28

5) Doran AC, Meller N, McNamara CA. Role of smooth muscle cells in the initiation and early progression of atherosclerosis. Arterioscler. Thromb. Vasc. Biol. 2008; 28: 812-819

6) Galkina E, Ley K. Vascular adhesion molecules in atherosclerosis. Arterioscler. Thromb. Vasc. Biol. 2007; 27: 2292-2301

7) Wong BW, Meredith A, Lin D, McManus BM. The Biological Role of Inflammation in Atherosclerosis. Can. J. Cardiol. 2012; 28: 631-641

8) Rudijanto A. The role of vascular smooth muscle cells on the pathogenesis of atherosclerosis. Acta Med. Indones. 2007; 39: 86-93

9) Lacolley P, Regnault V, Nicoletti A, Li Z, Michel JB. The vascular smooth muscle cell in arterial pathology: A cell that can take on multiple roles. Cardiovasc. Res. 2012; 95: 194-204

10) Chen WQ, Zhong L, Zhang L, Ji XP, Zhao YX, Zhang C, Jiang H, Wu YL, Zhang Y. Chinese medicine tongxinluo significantly lowers serum lipid levels and stabilizes vulnerable plaques in a rabbit model. J. Ethnopharmacol. 2009; 124: 103-110

11) Yin HQ, Wang B, Zhang JD, Lin HQ, Qiao Y, Wang R, Liu FY. Effect of traditional Chinese medicine Shu-MaiTang on attenuating TNF $\alpha$-induced myocardial fibrosis in myocardial ischemia rats. J. Ethnopharmacol. 2008; 118: 133-139

12) Zhang YH, Liu JT, Wen BY, Liu N. Mechanisms of inhibiting proliferation of vascular smooth muscle cells by serum of rats treated with Dahuang Zhechong pill. J. Ethnopharmacol. 2009; 124: 125-129

13) Wang Y, Zhao X, Wang YS, Song SL, Liang H, Ji AG. An extract from medical leech improve the function of endothelial cells in vitro and attenuates atherosclerosis in ApoE null mice by reducing macrophages in the lesions. Biochem. Biophys. Res. Commun. 2014; 455: 119-125

14) Griendling KK, Taubman MB, Akers M, Mendlowitz M, Alexander RW. Characterization of phosphatidylinositolspecific phospholipase C from cultured vascular smooth muscle cells. J. Biol. Chem. 1991; 266: 15498-15504

15) Ma S, Zhang D, Lou H, Sun L, Ji J. Evaluation of the anti-inflammatory activities of tanshinones isolated from Salvia miltiorrhiza var. alba roots in THP-1 macrophages. J. Ethnopharmacol. 2016; 188: 193-199

16) Choi HJ, Chung TW, Kim JE, Jeong HS, Joo M, Cha J, $\mathrm{Kim} \mathrm{CH}, \mathrm{Ha} \mathrm{KT}$. Aesculin inhibits matrix metalloproteinase-9 expression via p38 mitogen activated protein kinase and activator protein 1 in lipopolysachride-induced RAW 264.7 cells. Int. Immunopharmacol. 2012; 14: 267-274

17) Guo J, Li L, Wu YJ, Yan Y, Xu XN, Wang SB, Yuan TY, Fang LH, Du GH. Inhibitory Effects of Brazilin on the Vascular Smooth Muscle Cell Proliferation and Migration Induced by PDGF-BB. Am. J. Chin. Med. 2013; 41: 1283-1296

18) Zhu L, Sun G, Zhang H, Zhang Y, Chen X, Jiang X, Jiang X, Krauss S, Zhang J, Xiang Y, Zhang CY. PGC-1 $\alpha$ is a key regulator of glucose-induced proliferation and migration in vascular smooth muscle cells. PLoS One. 2009; 4: 1-7

19) Cho Y, Lee SE, Lee HC, Hur J, Lee S, Youn SW, Lee J, Lee HJ, Lee TK, Park J, Hwang SJ, Kwon YW, Cho HJ, Oh $\mathrm{BH}$, Park YB, Kim HS. Adipokine resistin is a key player to modulate monocytes, endothelial cells, and smooth muscle cells, leading to progression of atherosclerosis in rabbit carotid artery. J. Am. Coll. Cardiol. 2010; 57: 99-109

20) Förstermann U, Sessa WC. Nitric oxide synthases: Regulation and function. Eur. Heart J. 2012; 33: 829-837

21) Li H, Horke S, Förstermann U. Vascular oxidative stress, nitric oxide and atherosclerosis. Atherosclerosis. 2014; 237: 208-219

22) Jovanović I, Zivković M, Djurić T, Popović M, Alavantić D, Stanković A. CXCL16 in Vascular Pathology Research: from Macro Effects to microRNAs. J. Atheroscler. Thromb. 2015; 22: 1012-1024

23) Doyle SL, O'Neill LA. Toll-like receptors: From the discovery of NF- $\kappa$ B to new insights into transcriptional regulations in innate immunity. Biochem. Pharmacol. 2006; 72: $1102-1113$

24) Den Dekker WK, Cheng C, Pasterkamp G, Duckers HJ. Toll like receptor 4 in atherosclerosis and plaque destabilization. Atherosclerosis. 2010; 209: 314-320

25) Eguchi K, Manabe I. Toll-like receptor, lipotoxicity and chronic inflammation: the pathological link between obesity and cardiometabolic disease. J. Atheroscler. Thromb. 2014; 21: 629-639

26) Meng Z, Yan C, Deng Q, Gao D, Niu X. Curcumin inhibits LPS-induced inflammation in rat vascular smooth muscle cells in vitro via ROS-relative TLR4-MAPK/ NF- $\kappa$ B pathways. Acta. Pharmacol. Sin. 2013; 34: 901-911

27) Hansson GK, Hermansson A. The immune system in atherosclerosis. Nat. Immunol. 2011; 12: 204-212

28) Coll B, Alonso-Villaverde C, Joven J. Monocyte chemoattractant protein-1 and atherosclerosis: Is there room for an additional biomarker? Clin. Chim. Acta. 2007; 383: 21-29

29) Kleinbongard P, Heusch G, Schulz R. TNF $\alpha$ in atherosclerosis, myocardial ischemia/reperfusion and heart failure. Pharmacol. Ther. 2010; 127: 295-314

30) Wang Z, Castresana MR, Newman WH. NF- $\kappa$ B is required for TNF- $\alpha$-directed smooth muscle cell migration. FEBS. Lett. 2001; 508: 360-364

31) Kyriakis JM, Avruch J. Mammalian MAPK Signal Transduction Pathways Activated by Stress and Inflammation: A 10-Year Update. Physiol. Rev. 2012; 92: 689-737

32) Peng SC, Wong DS, Tung KC, Chen YY, Chao CC, Peng $\mathrm{CH}$, Chuang YJ, Tang CY. Computational modeling with forward and reverse engineering links signaling network and genomic regulatory responses: NF-kappaB signalinginduced gene expression responses in inflammation. BMC. Bioinformatics. 2010; 11: 308

33) De Winther MP, Kanters E, Kraal G, Hofker MH. Nuclear factor $\kappa \mathrm{B}$ signaling in atherogenesis. Arterioscler. Thromb. Vasc. Biol. 2005; 25: 904-914

34) Madonna R, De Caterina R. Relevance of new drug discovery to reduce NF- $\kappa \mathrm{B}$ activation in cardiovascular disease. Vascul. Pharmacol. 2012; 57: 41-47

35) Tak PP, Firestein GS. NF- $\kappa \mathrm{B}$ in defense and disease NF- $\kappa$ B: a key role in inflammatory diseases. J. Clin. Invest. 2001; 107: 7-11 